\title{
Pengaruh Penerapan Metode Pair Check Terhadap Kemampuan Pemahaman Membaca Peserta Didik Kelas V di Sekolah Dasar Negeri 37 Tungka Kabupaten Enrekang
}

\author{
Rahmat $^{1}$, Umiyati Jabri ${ }^{2}$, Firdayanti ${ }^{3}$ \\ 1,2,3 (Pendidikan Guru Sekolah Dasar, Pendidikan Bahasa Inggris, Universitas Muhammadiyah \\ Enrekang)
}

*Umiyati Jabri. E-mail: umiyatijabri@gmail.com

\begin{tabular}{|l|l|l|}
\hline Receive: 23/07/2021 & Accepted: 13/08/2021 & Published: 01/10/2021
\end{tabular}

\begin{abstract}
Abstrak
Penelitian ini merupakan jenis penelitian eksperimen dengan melibatkan satu kelompok atau satu kelas yang dikenal dengan desain Pra Eksperimen yang bertujuan untuk mengetahui Pengaruh metode Pair Check terhadap kemampuan pemahaman membaca peserta didik kelas V Sekolah Dasar Negeri 37 Tungka tahun ajaran 2020/2021. Hasil penelitian menunjukkan bahwa: (1) Skor rata-rata hasil pretest siswa kelas $V$ adalah 48,3 dengan standar deviasi 16 dimana skor paling rendah yang diperoleh adalah 10 dan skor paling tinggi adalah 70 dari skor ideal 100. Sedangkan, skor rata-rata posttest siswa kelas $V$ adalah 77,5 dengan standar deviasi 22 dimana skor paling rendah adalah 25 dan skor paling tinggi adalah 100 dengan skor ideal 100. Dari hasil tersebut diperoleh bahwa 12 siswa atau 80\% telah mencapai Kriteria Ketuntasan Minimal (KKM) dan ini berarti ketuntasan secara klasikal tercapai. (2) Rata-rata persentase aktivitas siswa yaitu 80\%, dengan kesimpulan aktivitas siswa telah mencapai kriteria aktif, sehingga dapat disimpulkan Metode pembelajaran pair check memberikan pengaruh terhadap kemampuan pemahaman membaca siswa kelas V SDN 37 Tungka Kabupaten Enrekang.
\end{abstract}

Kata Kunci: Pengaruh, metode pair check, pemahaman membaca

\begin{abstract}
This research is an experimental research type involving one group or one class known as the Pre-Experimental design which aims to determine the effect of the Pair Check method on the reading comprehension ability of the fifth grade students of 37 Tungka State Elementary School in the 2020/2021 academic year. The results showed that: (1) The average score of the pretest results of class $V$ students was 48.3 with a standard deviation of 16 where the lowest score obtained was 10 and the highest score was 70 from the ideal score of 100. Meanwhile, the average score The posttest of class $V$ students is 77.5 with a standard deviation of 22 where the lowest score is 25 and the highest score is 100 with an ideal score of 100. From these results it is obtained that 12 students or $80 \%$ have reached the Minimum Completeness Criteria (KKM) and this means classical completeness is achieved. (2) The average percentage of student activity is $80 \%$, with the conclusion that student activity has reached the active criteria, so it can be concluded that the pair check learning method has an influence on the reading comprehension ability of fifth grade students at SDN 37 Tungka, Enrekang Regency.
\end{abstract}

Keywords: Influence, pair check method, reading comprehension. 


\section{Pendahuluan}

Perkembangan Ilmu Pengetahuan dan Teknologi atau biasa disebut IPTEK menuntut agar semua masyarakat suka belajar. Pembelajaran yang baik salah satunya dilakukan dengan membaca. Masyarakat yang suka membaca memiliki banyak informasi. Dalman dalam Meliyawati (2016:1), berpendapat bahwa membaca merupakn suatu kegiatan atau proses kognititf yang berupayah untuk menemukan berbagai informasi yang terdapat dalam tulisan,

Membaca merupakan hal yang sangat penting dalam kehidupan bermasyarakat, setiap aspeknya itu melibatkan membaca. Rahim Farida (2011:11) memberikan contoh pentingnya membaca dalam kehidupan masyarakat, yaitu rambu jalan yang menuntun orang sedang bepergian sampai pada tujuan mereka, memberikan informasi pada pengendara tentang bahaya di jalan, serta mengingatkan peraturan lalu lintas. Membaca adalah proses meningkatkan pengetahuan yang berupayah menemukan berbagai macam informasi yang ada pada suatu tulisan. Hal ini juga memiliki arti membaca adalah suatu proses berfikir untuk memaknai bacaan yang dibaca. Karenanya, membaca tidak cuma untuk melihat kumpulan beberapa huruf membentuk kata, kalimat, paragraf, dan bacaan. Tapi lebih daripada itu, membaca adalah suatu kegiatan untuk memaknai tanda tulisan yang memiliki makna agar pesan yang disampaikan penulis diterima pembaca (Dalman, 2014:5). Tarigan (2015:8) juga menyatakan membaca merupakan metode yang dipergunakan untuk berkomunikasi dengan diri sendiri dan dengan orang lain untuk mengkomunikasikan makna yang terkandung pada lambang-lambang yang tertulis. Dari uraian tersebut, disimpulkan bahwa membaca merupakan proses memaknai suatu kata serta memadukannya kedalam sebuah kalimat, agar pembaca dapat mengerti teks yang sedang dibaca pada akhirnya mampu merangkum sebuah teks itu dengan bahasanya. Pembelajaran membaca menghadapi masalah dan hambatan.

Kenyataan praktis pada kelas V SDN 37 Tungka terdapat peserta didik yang kemampuan membacanya masih rendah. Pernyataan ini atas hasil observasi di SD dan melakukan wawancara pada wali kelas V (lima), dilakukan hari kamis 23 Januari 2020. Faktor penyebab dari kurangnya kemampuan membaca siswa adalah kelancaran dalam membaca kurang, pelafalan, dan juga intonasi dalam membaca masih belum tepat. Selain faktor tersebut salah satunya adalah kurangnya pemahaman terhadap bacaan yang dibaca. Guna mengatasi masalah tersebut, peneliti tergerak untuk melakukan peneliti menggunakan Metode pembelajaran kooperatif yaitu pair check. Pair Check merupakan suatu cara digunakan dalam membantu peserta didik yang pasif dalam belajar kelompok dengan bekerja sama berpasangan dan menerapkan kegiatan pengecekan berpasangan, dan metode pembelajaran Pair check peserta didik dapat melatih kemampuan membaca pemahaman. Istarani (2011)mengatakan, "Metode Pembelajaran Pair Check merupakan metode dengan membentuk kelompok berpasangan dimana dipopulerkan oleh Spencer Kagen tahun 1993". Metode Pair Check menggunakan pembelajaran berkelompok dimana mengajarkan siswa dalam kemandirian dan kemampuan untuk mengerjakan persoalan yang ada. Metode ini pun dapat melatih rasa sosial peserta didik, kerjasama serta kemampuan untuk memberi penilaian. Kurniasih dan Sani (2016:111) mengemukakan, metode Pair Check merupakan pembelajaran yang mengutamakan kerja kelompok. Peserta didik pada setiap kelompok harus mandiri dan mampu menyelesaikan soal yang diberikan oleh guru.

Berdasarkan permasalahan yang dihadapi siswa kelas V SDN 37 Tungka peneliti memprediksi dengan menggunakan penelitian yang bersifat eksperimen dengan judul "Pengaruh Penerapan Metode Pair Check Terhadap Kemampuan Pemahaman Membaca Peserta Didik Kelas V di SDN 37 Tungka" diharapkan mampu mengatasi masalah yang dihadapi peserta didik dalam kemampuan membaca.

\section{Metode}

Penelitian ini menggunakan metode eksperimen dengan pendekatan kuantitatif. Penelitian ini menerapkan design penelitian Praeksperiment, dengan jenis One-Group PretestPosttest Design. Sehingga hasil dari perlakuan didapat dengan lebih akurat karena membandingkan keadaan sebelum dan sesudah diberi perlakuaan (treatment). 
Adapun desainnya:

\section{$\mathrm{O} 1 \mathrm{X} \mathrm{O} 2$}

Keterangan:

$\mathrm{O} 1=$ Tes awal

$\mathrm{X}=$ Perlakuan (treatment) model pembelajaran

Pair Check.

$\mathrm{O} 2=$ Tes akhir

Populasi dalam penelitian ini yaitu keseluruhan peserta didik kelas V SDN 37 Tungka dimana jumlah siswa 12 orang, 6 perempuan dan 6 laki-laki, dengan sampel adalah 12 siswa kelas V. Instrumen dalam penelitian ini menggunakan Tes Membaca Pemahaman, Tes belajar dengan jenis pretest dan posttest. Sebelum model pembelajaran pair check diterapkan peneliti menggunakan Pretest, sedangkan setelah menerapkan model pembelajaran pair check maka peneliti menggunakan posttest. Observasi, Sugiyono (2018:229) menjelaskan bahwa, observasi merupakan suatu cara pengambilan data yang mempunyai ciri yang spesifik bila dibandingkan dengan cara yang lain. Selama pembelajaran berlangsung peneliti melakukan observasi, dengan memberikan tanda cek list $(\sqrt{ })$ jika criteria telah ada pada siswa. Penelitian ini menerapkan 2 test diantaranya tes awal dan tes akhir. Test awal (Pretest) diterapkan sebelum memberikan perlakuan kepada peserta didik. Pretest dilakukan guna mengetahui kemampuan peserta didik sebelum diterapkan metode pair check. Perlakuan (treatment) Penelitian ini menerapkan metode pair check terhadap peserta didik pada keterampilan membacanya, Setelah dilakukannya treatment, test akhir (posttest) diterapkan agar dapat mengetahui kemampuan membaca dengan menggunakan metode pair check.

Teknik analisis yang digunakan dua jenis, diantaranya: (1) Analisis statistic Deskriptif. Statistic deskriptif merupakan statistic yang digunakan dalam menganalisis data yang telah dikumpulkan dengan mendeskripsikannya. Penelitian ini sendiri menggunakan analisis statistic deskriptif agar dapat mendeskripsikan kemampuan membaca pemahaman peserta didik. (2) Analisis Statistic Inferensial Statistic inferensial merupakan statistic agar dipergunakan dalam mengelolah data sampel selanjutnya hasil akan digunakan pada populasi. Teknik ini dilakukan agar dapat menguji hipotesis dari penelitian, dengan analisis selisih anatar pretest dan posttest. Langkah-langkahnya sebagai berikut: Membuat tabulasi skor siswa, Melakukan perhitungan persentase nilai, Mengklasifikasikan nilai dengan standar penilaian, Melakukan uji normalitas agar diketahuinya data berdistribusi normal atau tidak, Melakukan uji t agar dapat mengetahui hipotesis diterima atau tidak, Menguji tingkat kesalahan (alpha) $=5 \%$, Bandingkan hasil $\mathrm{t}$ hitung dengan $\mathrm{t}$ table, Menentukan perbedaan hasil pretest dan posttest peserta didik terhadap kemampuan membaca pemahaman untuk menarik kesimpulannya. Kemudian dianalisis menggunakan aplikasi SPSS versi 20.

\section{Hasil dan Pembahasan Hasil}

Penelitian ini bersifat kuantitatif dimana data yang dihasilkan akan berbentuk angka. Hasil dari penelitian ini adalah guna mendeskripsikan kemampuan membaca peserta didik menggunakan metode Pair Check kelas V di SDN 37 Tungka, dalam penelitian ini 12 peserta didik dijadikan sampel, adapun hasil dari penelitian berupa data kuantitatif, selanjutnya data yang telah didapat akan dianalisis menggunakan prosedur yang telah ada, untuk peneliti menggunakan analisis statistic deskriptif dan analisis statistic inferensial. Analisis statistic deskriptif untuk mendeskripsikan kemampuan membaca pemahaman peserta didik melalui Metode Pembelajaran Pair Check. Sedangkan analisis statistic inferensial untuk menguji hipotesis penelitian dengan menganalisis selisih antara nilai posttest dan nilai Pretest. Pada saat Eksperimen dilakukan, siswa dibagi menjadi 2 orang dalam satu kelompok setiap pasangan mempunyai peran masing-masing ada yang menjadi partner atau mendengarkan cerita dan menjawab soal, ada juga yang menjadi pelatih atau yang membacakan teks bacaan dan mengecek jawaban. Setelah itu bertukar peran/posisi, partner menjadi pelatih sedangkan pelatih menjadi partner. Kemudian guru memberikan kesimpulan serta saran dari jawaban peserta didik dari beberapa soal. Sebelum menggunakan model pair check dalam proses pembelajaran terlebih dulu diberikan soal pretest.

Hasil Pretest kemampuan membaca pemahaman siswa dikumpulkan kedalam lima kategori, yaitu: 


\begin{tabular}{|c|c|c|c|c|}
\hline No & Skor & Kategori & Frekuensi & Persentase \\
\hline 1. & $0-55$ & $\begin{array}{l}\text { Sangat } \\
\text { rendah }\end{array}$ & 7 & $58,3 \%$ \\
\hline 2. & $56-65$ & Rendah & 2 & $16,7 \%$ \\
\hline 3. & $66-80$ & Sedang & 3 & $25 \%$ \\
\hline 4. & $81-90$ & Tinggi & 0 & $0 \%$ \\
\hline 5. & $\begin{array}{l}91- \\
100\end{array}$ & $\begin{array}{c}\text { Sangat } \\
\text { tinggi }\end{array}$ & 0 & $0 \%$ \\
\hline \multicolumn{3}{|c|}{ Jumlah } & 12 & $100 \%$ \\
\hline
\end{tabular}

Tabel di atas menunjukkan skor hasil Pretest kemampuan membaca pemahaman peserta didik sebelum diberikan perlakuan dari 12 siswa, 7 peserta didik masuk dalam kategori sangant rendah dimana presentasenya $58,3 \%, 2$ peserta didik masuk dalam kategori yang rendah dengan persentase $16,7 \%, 3$ peserta didik masuk pada kategori sedang dengan persentase $25 \%, 0$ peserta didik yang mendapat kategori tinggi persentase $0 \%, 0$ peserta didik masuk pada kategori sangat tinggi persentase $0 \%$. Hal ini berarti hasil Pretest kemampuan membaca pemahaman siswa sebelum diberikan perlakuan pada umunya (sebagian besar) 7 orang yang berada dalam kategori sangat rendah. Kemudian diberikan soal Posttest dimana siswa sudah diberikan perlakuan atau menerapkan model pair check, dan didapatkan hasil posttest kemampuan membaca pemahaman siswa dikumpulkan kedalam lima kategori, yaitu:

\begin{tabular}{|c|c|c|c|c|}
\hline No & Skor & Kategori & Frekuensi & Persentase \\
\hline 1. & $0-54$ & $\begin{array}{l}\text { Sangat } \\
\text { rendah }\end{array}$ & 1 & $8,3 \%$ \\
\hline 2. & $55-64$ & Rendah & 2 & $16,8 \%$ \\
\hline 3. & $65-79$ & Sedang & 1 & $8,3 \%$ \\
\hline 4. & $80-89$ & Tinggi & 4 & $33,3 \%$ \\
\hline 5. & $\begin{array}{l}90- \\
100 \\
\end{array}$ & $\begin{array}{c}\text { Sangat } \\
\text { tinggi }\end{array}$ & 4 & $33,3 \%$ \\
\hline \multicolumn{3}{|c|}{ Jumlah } & 12 & $100 \%$ \\
\hline
\end{tabular}

Pada table di atas dapat dilihat bahwa dari 12 siswa yang digunakan pada kelas eksperimen umumnya mempunyai tingkat kemampuan membaca pada kategori yang tinggi dengan frekuensi 4 siswa $(33,3 \%)$ dan kategori yang sangat tinggi dengan frekuensi 4 siswa $(33,3 \%)$.
Kemudian untuk persentase kemampuan siswa secara klasikal dapat dilihat pada berikut:

\begin{tabular}{|c|c|c|c|}
\hline Skor & Kategorisasi & Frekuensi & $\begin{array}{c}\text { Persentase } \\
(\mathbf{\%})\end{array}$ \\
\hline $0 \leq \mathrm{x}<70$ & Belum mampu & 3 & $25 \%$ \\
\hline $70 \leq \mathrm{x} \leq 100$ & Mampu & 9 & $75 \%$ \\
\hline \multicolumn{2}{|c|}{ Jumlah } & 12 & $100 \%$ \\
\hline
\end{tabular}

Berdasarkan tabel tersebut dapat dilihat 9 peserta didik telah mampu untuk tuntas dari jumlah total 12 siswa dengan persentase $75 \%$. Jika dikaitkan dengan kemampuan peserta didik yang ditetapkan, maka kemampuan siswa secara keseluruhan dianggap mampu.

Sebelum analisis statistic inferensial digunakan, lebih dulu dilakukan uji asumsii,

Uji Normalitas, Uji ini dilakukan pada nilai kelompok agar dapat mengetahui populasi data berdistribusi normal atau tidak. Perhitungan ini dilakukan menggunakan aplikasi SPSS 20. Kriteria pengujiannya merupakan data berdistribusi normal jika $p$-value $>\alpha$ (taraf signifikansi $\alpha=0,05$ ).

\begin{tabular}{|l|c|c|c|c|c|c|}
\hline \multicolumn{7}{|c|}{ Tests of Normality } \\
\hline & \multicolumn{2}{|c|}{ Kolmogorov-Smirnov } & \multicolumn{2}{|c|}{ Shapiro-Wilk } \\
\cline { 2 - 7 } & Statistic & Df & Sig. & Statistic & Df & Sig \\
\hline $\begin{array}{l}\text { Pret } \\
\text { est }\end{array}$ &, 226 & 12 &, 093 &, 883 & 12 &, 09 \\
\hline $\begin{array}{l}\text { Post } \\
\text { test }\end{array}$ &, 211 & 12 &, 144 &, 883 & 12 &, 09 \\
\hline \multicolumn{2}{|l|}{ a. Lilliefors Significance Correction } \\
\hline
\end{tabular}

Sehingga, hasil yang didapatkan untuk nilai pretest yaitu $0,097>0,05$, sehingga ditarik kesimpulannya bahwa nilai pretest termasuk kategori normal. Pada hasil analisis posttest menunjukkan 0,095 > 0,05, lalu disimpulkan nilai posttest masuk pada kategori normal.

Uji t test, Uji $T$ test menerapkan taraf signifikansi $5 \%$ atau 0,05 . Selanjutnya didapat thitung 6,31 (lihat lampiran hasil analisis). Selanjutnya untuk menetukan ttabel diperoleh pada $\alpha=0,05$ atau $5 \%$ dengan df atau deraja kebebasan $\mathrm{n}-1$ atau $12-1=11$. Hasil ttabel adalah 2,200. Sedangkan kriteria dari pengujian, H0 ditolak jika thitung $>$ t tabel maka Ha diterima dan 
Ho ditolak, sebaliknya thitung $<$ ttabel maka Ha ditolak dan Ho diterima. Sehingga uji t hitung $>\mathrm{t}$ tabel atau tabel $<\mathrm{t}$ hitung $(6,31>2,200$ atau $2,200<6,31)$, oleh karena itu nilai H0 ditolak dan Ha diterima.

\section{Pembahasan}

Menurut Huda (2013:211) Pair Check adalah metode pembelajaran berkelompok antardua orang atau berpasangan, yang dapat melatih tanggung jawab social peserta didik, kerja sama dan kemampuan member penilaian.

Dipilihnya model pembelajaran Pair Checks dikarenakan pembelajaran dengan tipe ini akan mendapatkan suatu pengalaman belajar yang lebih menarik dari pembelajaran biasanya. Karena pada pembelajaran Pair Checks ini memiliki kelebihan yaitu siswa belajar secara berkelompok dan berpasangan. Jadi pembelajaran secara berkelompok dan berpasangan ini dapat membantu siswa yang pasif dalam pembelajaran menjadi lebih aktif. Dengan pembagian kelompok dan pasangan ini dimaksudkan agar terjadi keseimbangan dalam tiap kelompok, dimana siswa yang pandai dapat membantu atau mengajari siswa yang kurang pandai dan menekankan siswa untuk dapat mengerjakan soal dengan baik. Pemahaman didalam belajar sangatlah penting dari pada sekedar menghafal. Dengan memahami siswa akan mampu menguasai materi dengan baik. Kelebihan dalam model pembelajaran Pair Checks ini adalah siswa belajar dipandu rekan dan melatih siswa berkomunikasi dengan baik dengan teman.

Dalam pembelajaran Pair Checks ini, setiap pasangan memiliki peran masing-masing, ada yang berperan menjadi partner (siswa yang mengerjakan soal) dan coach (pelatih). Pelatih ini yang membantu mengkoreksi pekerjaan si partner. Jika ada pekerjaan yang salah maka coach yang membantu memperbaiki dan menjelaskan jawaban yang sebenarnya. Kemudian, antara si partner dan coach tadi bertukar peran, parntner menjadi coach dan coach menjadi partner dengan tugas masingmasing. Dari langkah inilah yang dapat membantu meningkatkan keterampilan siswa, karena setiap pasangan dapat membantu pasangannya dalam mengerjakan soal yang diberikan guru. Siswa yang awalnya tidak tahu menjadi tahu dan memiliki keterampilan baru.
Adapun di dalam penelitian ini untuk melihat keaktifan pembelajaran secara kualitatif dapat dilihat dari perbandingan antara RPP dan juga lembar observasi. Hasil dari observasi menunjukan bahwa proses pembelajaran dapat berjalan dengan baik yaitu $80 \%$ dan juga sudah dapat menjalankan sintak-sintak yang sesuai dengan RPP. Skor posttest terendah dan tertinggi yaitu 25 dan 100, dengan nilai rata-rata 77,5 dan standar deviasi 22.

Hal ini sejalan dengan penelitian yang relevan oleh Hal ini sejalan dengan penelitian yang relevan oleh Wimbo Sirating Sito Resmi (2019), dalam jurnal PGSD yang mengatakan bahwa rata - rata nilai pretest pada kelas cuma 53 sedangkan nilai posttest dalam kelas penelitian mengalami peningkatan sebesar 70,75, pada ketuntasan klasical saat pretest Cuma 20\% sedangkan saat posttest naik menjadi $85 \%$. Maka dapat ditarik kesimpulannya model pair check baik digunakan dalam peningkatan membaca pemahaman peserta kelas V SD Negeri Rejosari 03 Kota Semarang. Proses pembelajaran yang baik tidak hanya diukur dari skor akhir yang telah didapatkan peserta didik, tetapi juga dilihat dari bagaimana aktivitas para peserta didik selama pembelajaran menggunakan Metode Pembelajaran Pair Check. Berdasarkan analisis observasi pada aktivitas siswa selama pembelajaran menerapkan Metode Pair Check, dapat diperoleh bahwa selama 3 kali pertemuan yang dilakukan persentase keaktifan siswa sebesar $80 \%$ dari berbagai aspek yang diamati, persentase ini cukup tinggi untuk melihat aktif atau tidaknya peserta didik pada proses pembelajaran. Hal ini dikarenakan setiap peserta didik benar-benar ikut ambil bagian pada proses pembelajaran dengan Model Pair Check.

\section{Penutup}

\section{Simpulan}

Pada hasil analisis data serta pembahasan tersebut, ditarik kesimpulan, bahwa Penerapan Metode Pembelajaran Pair Check terhadap Kemampuan Pemahaman Membaca Peserta didik Kelas V SDN 37 Tungka, berpengaruh pada Kemampuan Membaca Peserta didik.

Adapun Kelebihan dan kelemahan selama proses penelitian yaitu, kelebihannya guru banyak membatu peneliti dalam proses pengumpulan data dan proses pembelajaran, peserta didik juga sangat antusias dalam proses penelitian, sedangkan untuk 
kelemahannya adalah kurangnya informasi yang diberikan mengenai karakter peserta didik sehingga pada proses penelitian ada sedikit kendala bagi peneliti.

\section{Saran}

Pada kesimpulan tersebut, terdapat beberapa saran, diantaranya: Pembelajaran menerapakan Metode Pair check dapat berdampak baik pada kemampuan membaca pemahaman, oleh karenanya guru harus bisa menerapkan metode pembelajatan tersebut kedalam pembelajaran. Untuk Peneliti selanjutnya, sebelum melakukan penelitian terlebih dahulu melakukan observasi baik dari segi nilai dan karakter peserta didik, peneliti harus mengetahui karakter peserta didiknya agar lebih mudah dalam penyampaian materi dan tidak ada kendala dalam proses penelitian.

\section{Daftar Pustaka}

[1] Kurniasih Imas dan Berlin Sani. (2016). Ragam Pengembangan Model Pembelajaran untuk Peningkatan Profesionalitas Guru. Surabaya: Kata Pena

[2] Maksudin. (2013). Pendidikan Karakter NonDikotomik. Yogyakarta: Pustaka Pelajar

[3] Meliyawati. (2016). Pemahaman Dasar Membaca (Edisi Versi). Yogyakarta: Grup Penerbit CV Budi Utama.

[4] Miftahul Huda. (2013). Model-Model Pengajaran dan Pembelajaran Yogyakarta: Pustaka Pelajar.

[5] Sukmadinata. (2010). Metode Penelitian Pendidikan. Bandung: PT Remaja Rosdakarya.

[6] Sumadyo, Samsu. (2011). Strategi dan Teknik Pembelajaran Membaca. Yogyakarta: Graha Ilmu.

[7] Wimbo Sirating Sitoresmi. (2019). Dalam Jurnal PGSD. Keefektifan Model Pair Check Pada Kemampuan Pemahaman Membaca

[8] Sugiyono. (2014). Metode Penelitian Pendidikan, Bandung: Alfabeta

[9] Sugiyono. (2018). Metode Penelitian Kuantitatif. Bandung: Alfabeta

[10] Sukmadinata. (2010). Metode Penelitian Pendidikan. Bandung: PT Remaja Rosdakarya.

\section{Profil Penulis}

Rahmat lahir di Jalikko, 22 Mei 1986 yang saat ini berstatus sebagai dosen Universitas Muhamadiyah Enrekang jurusan PGSD (Pendidikan Guru Sekolah Dasar). Bersama dengan ibu Umiyati Jabri yang merupakan dosen PBI Universitas Muhamadiyah Enrekang. Bersama dengan Firdayanti sebagai mahasiswa pada jurusan PGSD. Demikian profil singkat dari penulis, terimakasih semoga bermanfaat bagi kita semua. 